\title{
CONCENTRAÇÃO DE CÁLCIO NAS FRATURAS DE FÊMUR PROXIMAL ATENDIDOS EM UM HOSPITAL PÚBLICO DO EXTREMO SUL DA BAHIA
}

\author{
AUTOR: ISABELLE RODRIGUES RONACHER \\ CO-AUTOR/ORIENTADOR: WILLIAM RODRIGUES DE FREITAS
}

\begin{abstract}
Resumo: A osteoporose é um distúrbio comum nos idosos e mais frequente na mulher após a menopausa devido à diminuição dos estrógenos. A fragilidade do esqueleto ósseo predispõe à fraturas, em especial a de quadril por causa do grande impacto sobre os pacientes, maior mortalidade, dependência, risco de institucionalização, com aumento substancial dos custos econômicos e sociais. A baixa massa óssea e a recorrência de quedas são os principais fatores associados às fraturas de fêmur proximal em idosos. A etiologia está relacionada com a diminuição dos níveis séricos de cálcio, menor produção de vitamina D, e aumento da secreção de paratormônio. Os fatores de risco para fraturas patológicas são as causas de quedas em idosos: fratura prévia, sedentarismo, uso de medicamentos que afetam equilíbrios e cognição, desordens neurovegetativas, instabilidade da marcha, baixa acuidade visual e taquicardia ao repouso. Dessa forma, as fraturas de quadril em idosos podem ser fatais, atreladas à morbidade pela imobilização e restrição ao leito, diminuindo consideravelmente a qualidade de vida do idoso. Assim, a prevenção ou tratamento efetivo da osteoporose necessita de uma ingesta de cálcio adequada para manter ou restaurar a saúde do esqueleto ósseo, além de um estilo de vida saudável, com uma alimentação equilibrada e prática regular de atividades físicas que são medidas importantes à prevenção desta doença.
\end{abstract}

Palavras-chave: Fratura, fêmur, idosos, Teixeira de Freitas. 